\title{
COMPOSIÇÃO MINERAL DA CARCAÇA E DOS CORTES DA CARCAÇA DE OVINOS JOVENS E ADULTOS
}

\author{
Rafael Silvio Bonilha Pinheiro ${ }^{1}$, Americo Garcia da Silva Sobrinho ${ }^{2}$, \\ Ernani Nery de Andrade ${ }^{3}$ \\ 1 Universidade Estadual Paulista - Campus de Ilha Solteira - rafaelsbp@gmail.com \\ 2 Universidade Estadual Paulista - Campus de Jaboticabal \\ 3 Universidade Estadual Paulista - Campus de Botucatu
}

\begin{abstract}
RESUMO: Com o objetivo de estudar a composição mineral (ferro, cálcio e sódio) da carcaça e dos cortes da carcaça de ovinos de diferentes categorias, utilizaram-se 18 ovinos $1 / 2$ lle de France $1 / 2$ Ideal ( 6 cordeiros não castrados, 6 ovelhas adultas de descarte e 6 capões adultos de descarte). Os animais foram criados em regime de pasto de Tifton -85 e suplementados com concentrado. Os cordeiros foram abatidos aos $32 \mathrm{~kg}$, com aproximadamente 5 meses de idade. As ovelhas e capões, com $55 \mathrm{~kg}$ e 60 meses de idade. Os valores de ferro diferiram entre as categorias quanto aos músculos dos cortes estudados, com maior média para os músculos da perna dos ovinos adultos de $3,86 \mathrm{mg} / 100 \mathrm{~g}$ em relação aos dos cordeiros de $1,91 \mathrm{mg} / 100 \mathrm{~g}$, respectivamente. Os teores de ferro nos músculos da meia carcaça não diferiram quanto à categoria animal, com média de 3,38 $\mathrm{mg} / 100 \mathrm{~g}$. Os valores de cálcio nos músculos da meia carcaça e do corte da perna foram superiores para os capões $(9,84$ e $7,35 \mathrm{mg} / 100 \mathrm{~g})$, intermediários para ovelhas $(6,28$ e $6,54 \mathrm{mg} / 100 \mathrm{~g})$ e com os menores teores para os cordeiros $(5,30$ e $4,22 \mathrm{mg} / 100 \mathrm{~g})$. Não houve diferenças quanto aos teores de sódio para as categorias e diferentes músculos estudados, com valor médio de $56,75 \mathrm{mg} / 100 \mathrm{~g}$. Concluiu-se que os valores de sódio são similares entre as categorias animais e entre os diferentes músculos da carcaça, e que os de ferro e cálcio apresentam diferenças.
\end{abstract}

Palavras-chave: categorias animais; minerais; músculos; ovelhas

\section{MINERAL COMPOSITION OF THE CARCASS AND CARCASS CUTS FROM YOUNG AND ADULT SHEEPS}

\begin{abstract}
Aiming to evaluate the mineral composition (iron, calcium and sodium) of the carcass and carcass cuts of meat from different ovine categories, 18 1 1/2 lle de France $1 / 2$ Polwarth sheeps (6 uncastrated lambs, 6 discarded ewes and 6 discarded wethers) were used. Animals were in grazing system based on Tifton - 85 pastures and were supplemented with concentrate. Lambs were slaughtered at $32 \mathrm{~kg}$ of live weight, at around 5 months of age. Ewes and wethers were slaughtered with $55 \mathrm{~kg}$ and 60 months of age. The iron values were differents between categories for those valued cuts muscles, with higher average to legs muscles from adults ovine of $3.86 \mathrm{mg} / 100 \mathrm{~g}$ with regard to lambs of $1.91 \mathrm{mg} / 100 \mathrm{~g}$, respectively. The iron values of the muscles from half carcass didn't differ for that animal category, with $3.38 \mathrm{mg} / 100 \mathrm{~g}$ average. The calcium values in muscles from half carcass and leg cut were higher to wethers $(9.84 \mathrm{e} 7.35 \mathrm{mg} / 100 \mathrm{~g})$, intermediaries to ewes $(6.28 \mathrm{e}$ $6.54 \mathrm{mg} / 100 \mathrm{~g}$ ) and smallers values to lambs $(5.30$ e $4.22 \mathrm{mg} / 100 \mathrm{~g})$. There wasn't differences for sodium values to valued categories and muscles, with values around $56.75 \mathrm{mg} / 100 \mathrm{~g}$. In conclusion, the sodium values are similar between animals categories and from differents carcass muscles and that the iron and calcium values present differences.
\end{abstract}

Key Words: animal categories; ewes; minerals; muscles 


\section{INTRODUÇÃO}

Os minerais representam a menor fração da composição da carne, porém são de grande importância na alimentação humana, destacando-se o elemento ferro, por ser essencial para diversas funções do organismo, como suporte do sistema imunológico, formação parcial da hemoglobina dos glóbulos vermelhos, responsável pelo transporte de oxigênio e dióxido de carbono. Na carne, o ferro é encontrado na forma "heme" de mais fácil absorção pelo organismo humano do que o ferro "não heme" encontrado nos vegetais (Valle, 2000; Domene, 2006).

São escassas as informações, na literatura, sobre a composição mineral dos cortes comerciais da carcaça ovina, as quais poderiam contribuir para novos estudos e para aumentar a competitividade desta carne frente às demais fontes de proteína animal (Pinheiro et al., 2007a).

A Agência Nacional de Vigilância Sanitária aprovou em 2001 o regulamento para rotulagem nutricional obrigatória de alimentos embalados, considerando a necessidade de sua padronização dos nutrientes e componentes (carboidratos, proteínas, gorduras totais, colesterol, fibra alimentar, cálcio, ferro e sódio). Informações nutricionais sobre a carne ovina, disponibilizadas nos locais de comercialização, são raras, e estas apresentariam contribuição relevante à pesquisa, à empresa e ao consumidor, haja vista o crescimento desta espécie animal em decorrência da maior demanda de sua carne em relação à oferta (Pinheiro et al., 2007b). Portanto, realizou-se este trabalho com o objetivo de determinar a composição mineral (ferro, cálcio e sódio) da carcaça e dos cortes da carcaça de ovinos de diferentes categorias.

\section{MATERIAL E MÉTODOS}

Utilizaram-se 18 ovinos, produtos do cruzamento das raças lle de France $x$ Ideal (6 cordeiros não castrados, desmamados, com aproximadamente $17 \mathrm{~kg}, 6$ ovelhas e 6 capões, ambos de descarte com peso aproximado de 55 $\mathrm{kg})$. Os animais foram everminados, permanecendo em regime de pasto de Tifton - 85 (Cynodon dactylon cv.), no sistema de lotação intermitente, até o momento do abate.

Os ovinos receberam, diariamente, $1 \%$ do peso corporal de suplementação concentrada, fornecida às $17 \mathrm{~h}$, em cochos de madeira que permitiam 0 acesso de todos os animais ao mesmo tempo; um dos cochos foi colocado dentro de um cercado móvel de madeira, de 1,5 m de largura $\times 3,8 \mathrm{~m}$ de comprimento, com ripas de madeira distanciadas $20 \mathrm{~cm}$ uma da outra no sentido vertical, o que permitiu que apenas os cordeiros tivessem acesso ao concentrado oferecido nesse cocho.

As amostras dos concentrados e da pastagem foram coletadas para determinação dos teores de matéria seca, proteína bruta, extrato etéreo, cinzas, fibra em detergente neutro e fibra em detergente ácido, conforme Silva e Queiroz (2002). A composição centesimal e bromatológica das dietas experimentais dos cordeiros e dos animais adultos, expressas em porcentagem de matéria seca encontram-se na Tabela 1.

A amostragem da pastagem foi realizada pelo método do quadrado, conforme Gastaldi (1996). A composição bromatológica da forragem Tifton - 85 foi de $24,3 \%$ de matéria seca, $8,5 \%$ de matéria mineral, $9,2 \%$ de proteína bruta, $1,4 \%$ de extrato etéreo, $74,8 \%$ de fibra em detergente neutro e de $41,3 \%$ de fibra em detergente ácido.

Os cordeiros foram abatidos quando atingiram $32 \mathrm{~kg}$ de peso corporal, após jejum de 16 horas de die- 
Tabela 1 - Composição centesimal e bromatológica dos ingredientes das dietas experimentais (\% matéria seca)

\begin{tabular}{lcc}
\hline Ingrediente (\%) & \multicolumn{2}{c}{ Dieta } \\
\cline { 2 - 3 } & $\mathrm{d} 1^{(1)}$ & $\mathrm{d} 2^{(2)}$ \\
\hline Grão de milho moído & 54,8 & 60,8 \\
Farelo de trigo & 17,9 & 21,2 \\
Farelo de soja & 24,7 & 15,4 \\
Calcário calcítico & 1,5 & 1,5 \\
Fosfato bicálcico & 0,1 & 0,1 \\
Sal & 0,5 & 0,5 \\
Suplemento mineral ${ }^{(3)}$ & 0,5 & 0,5 \\
\hline Composição bromatológica (\%) & & \\
\hline MS & 87,9 & 86,4 \\
Cinzas & 3,7 & 15,9 \\
PB & 20,0 & 3,1 \\
EE & 3,2 & 16,9 \\
FDN & 16,7 & 6,7 \\
FDA & 6,0 & \\
(1) D1= Dieta para cordeiro jovem não castrado. ${ }^{(2)} \mathrm{D} 2=$ Dieta para ovelha e capão adulto. & $(3)$ Suplemento mineral: \\
zinco 1.600 mg, cobre 600 mg, manganês 1.500 mg, ferro 1.100 mg, cobalto 10 mg, iodo 27 mg, sódio 62 g e &
\end{tabular}

ta sólida. A insensibilização foi realizada por meio de eletronarcose, quando então foram seccionadas as veias jugulares e as artérias carótidas para sangria. Os cordeiros tiveram seus abates intercalados com os ovinos adultos. Os cordeiros foram abatidos com aproximadamente 5 meses de idade e as ovelhas e os capões, com aproximadamente 60 meses de idade.

Após a esfola, evisceração e retirada da cabeça e extremidades dos membros, as carcaças foram transferidas para câmara fria a $4^{\circ} \mathrm{C}$ por 24 horas. Ao final desse período, as carcaças foram divididas longitudinalmente em duas partes, sendo a metade direita seccionada em cinco regiões anatômicas, conforme Garcia (1998): paleta, pescoço, costelas, lombo e perna. Da outra metade da carcaça coletou-se parte de todos os músculos da mesma (aproximadamente $1 \mathrm{~kg}$ ) para que a amostra composta fosse analisada posteriormente.

Os músculos da meia carcaça esquerda e os cortes (paleta, perna e lombo) da meia carcaça direita de cada animal foram identificados, armazenados em sacos plásticos e congelados em freezer $\mathrm{a}-18^{\circ} \mathrm{C}$, por quatro meses, para facilitar as atividades posteriores nas análises de minerais da carne.

Os cortes foram descongelados em geladeira a $10^{\circ} \mathrm{C}$, por 20 horas, dentro dos sacos plásticos. Após esse período, com auxílio de bisturi e faca foram separadas amostras de todos os músculos da paleta, da perna e do lombo. Em seguida, foram identificadas individualmente e trituradas em multiprocessador para homogeneização visando às análises dos minerais da carne, assim como dos músculos da meia carcaça esquerda.

O preparo de solução mineral para quantificar os teores de ferro, cálcio e sódio foram conforme metodologia descrita por Silva e Queiroz (2002) e a leitura realizada em espectrofotômetro de absorção atômica, modelo GBC 932AA.

O delineamento experimental foi 0 inteiramente casualizado em esquema fatorial $3 \times 4$ (3 categorias animais e 4 cortes da carcaça).

As comparações de médias dos tratamentos foram pelo teste Tukey a $5 \%$ de probabilidade e as análises de variância segundo procedimento do SAS (SAS, 1996). 
Tabela 2- Médias dos teores de ferro, cálcio e sódio dos músculos da meia carcaça e dos cortes do lombo, paleta e perna de ovinos de diferentes categorias, expressas em $\mathrm{mg} / 100 \mathrm{~g}$ de carne

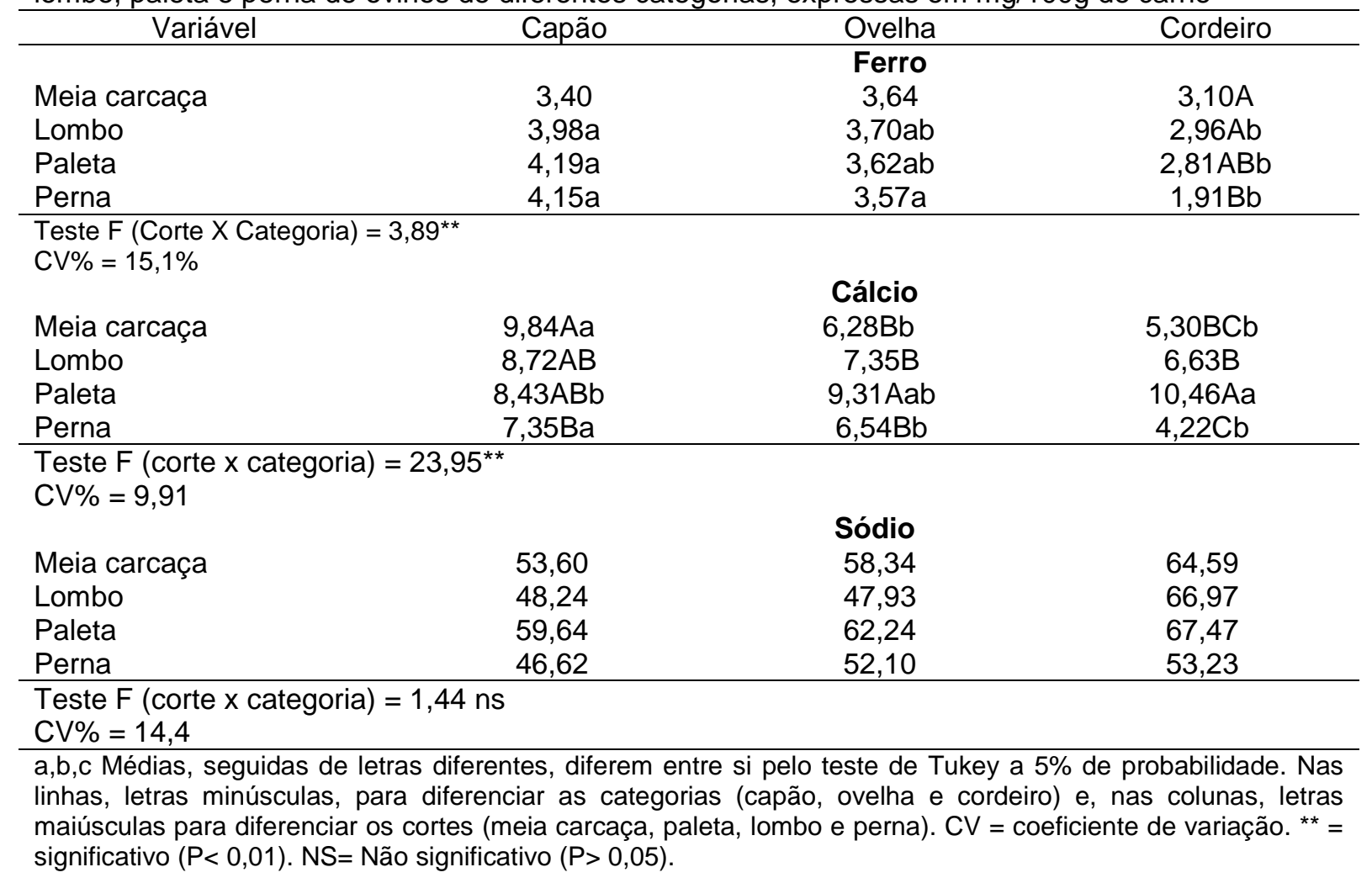

\section{RESULTADOS E DISCUSSÃO}

As médias dos teores de ferro, cálcio e sódio dos músculos da meia carcaça esquerda e dos cortes (lombo, paleta e perna) da carcaça direita de ovinos de diferentes categorias encontram-se na Tabela 2.

Os valores de ferro diferiram $(\mathrm{P}<$ $0,01)$ entre as categorias quanto aos músculos do corte da perna, com maior valor do teor de ferro para os ovinos adultos $(3,86 \mathrm{mg} / 100 \mathrm{~g})$ em relação aos dos cordeiros (Tabela 2). Madruga et al. (2002), ao avaliarem o teor de ferro na carne caprina, constataram diferenças entre animais abatidos aos 175 dias e aos 310 dias, com menor valor para os animais mais jovens $(1,87 \mathrm{mg} / 100 \mathrm{~g})$ e maior para os mais velhos $(3,65$ $\mathrm{mg} / 100 \mathrm{~g}$ ), semelhantes aos resultados obtidos entre os ovinos jovens e adultos deste estudo (Tabela 2) para os músculos do corte da perna. As ovelhas e cordeiros apresentaram valores de ferro similares $(P>0,05)$ entre os músculos do lombo e da paleta, com médias de 3,33 e $3,21 \mathrm{mg} / 100 \mathrm{~g}$, respectivamente. Os teores de ferro nos músculos da meia carcaça não diferiram $(P>0,05)$ quanto à categoria animal, com média de $3,38 \mathrm{mg} / 100 \mathrm{~g}$.

$O$ teor de ferro diferiu $(P<0,01)$ para os músculos dos cortes avaliados dos cordeiros (Tabela 2), com maiores valores para a meia carcaça e para o corte do lombo do que os músculos da perna. Os músculos dos animais adultos não diferiram $(P>0,05)$ quanto aos valores de ferro dos cortes avaliados, com médias de $3,93 \mathrm{mg} / 100 \mathrm{~g}$ para capões e de $3,63 \mathrm{mg} / 100 \mathrm{~g}$ para ovelhas. Teores inferiores (ao deste estudo) de ferro na carne caprina foram encontrados por Almeida (1990) nos cortes da paleta e da perna e também aos relatados por Dornelles e Moreira 
(2004) na carne de ovinos (2,5 $\mathrm{mg} / 100 \mathrm{~g}$ ).

O valor de cálcio nos músculos da meia carcaça foi superior $(P<0,01)$ para os capões, intermediários para ovelhas e com os menores teores para os cordeiros (Tabela 2). Os músculos do lombo não influenciaram os valores de cálcio entre as diferentes categorias, com teor média de $7,56 \mathrm{mg} / 100 \mathrm{~g}$. Os músculos da paleta não diferiram ( $P>$ $0,05)$ quanto aos teores de cálcio entre ovelhas e cordeiros.

Os capões apresentaram valores superiores $(P<0,05)$ de cálcio nos músculos da perna que os cordeiros (Tabela 2). Madruga et al. (2002) não verificaram aumento dos teores de cálcio na carne de caprinos abatidos aos 220, 265 e 310 dias de idade, com média de $3,90 \mathrm{mg} / 100 \mathrm{~g}$, inferior aos valores descritos por Dornelles e Moreira (2004), que relataram teores de $7 \mathrm{mg} / 100 \mathrm{~g}$ de cálcio na carne de carneiros, similares aos valores obtidos neste estudo.

Os valores de cálcio nos músculos dos cortes da carcaça dos capões foram próximos $(P>0,05)$, com exceção dos teores de cálcio da meia carcaça $(\mathrm{P}<0,01)$ e da perna (Tabela 2). Os teores de cálcio foram superiores $(\mathrm{P}<0,01)$ para os músculos da paleta das ovelhas em relação aos músculos dos demais cortes estudados, que não diferiram entre si $(P>0,05)$, com valor médio de $6,72 \mathrm{mg} / 100 \mathrm{~g}$. Os valores de cálcio nos músculos da paleta dos cordeiros foram superiores $(P<0,01)$ aos dos demais cortes (Tabela 2). Beserra et al. (2000), ao estudarem a qualidade da carne de cabritos da raça Moxotó e de cruzas Pardo Alpino x Moxotó, obtiveram teores de cálcio próximos aos valores relatados por Madruga et al (2006) na carne de cordeiros e aos deste trabalho, tanto para os animais jovens como para os adultos (Tabela 2).

Não houve diferenças $(P>0,05)$ quanto aos teores de sódio para as categorias animais (capão, ovelha e cordeiro) e músculos estudados, com valor médio de $56,75 \mathrm{mg} / 100 \mathrm{~g}$. Marcantonio (1998) relatou que a carne de bubalinos e bisões apresentaram teores médios de sódio de 56 e 57 $\mathrm{mg} / 100 \mathrm{~g}$, respectivamente, similares, portanto, aos resultados obtidos neste trabalho.

\section{CONCLUSÃO}

Os músculos dos cortes da carcaça (lombo, paleta e perna) dos capões apresentam maior teor de ferro que os mesmos cortes da carcaça dos cordeiros, indicando que a categoria animal pode alterar a composição deste mineral na carne. $O$ teor de sódio da carne é similar entre os diferentes cortes da carcaça e também entre as categorias ovinas estudadas.

\section{REFERÊNCIAS}

\section{ALMEIDA, M.M.M. Estudo da composição química das carnes de caprinos e ovinos no sertão do Ceará. 1990. 78 f. Dissertação de Mestrado. Universidade Federal do Ceará.}

BESERRA, F.J.; MONTE, A.L.S.; BEZERRA, L.C.N.M. et al. Caracterização química da carne de cabrito da raça Moxotó e de cruzas Pardo Alpino x Moxotó. Pesquisa Agropecuária Brasileira, v.35, n.1, p.171-177, 2000.

BRASIL. Resolução da Diretoria Colegiada da Agência Nacional de Vigilância Sanitária n․ 40, de 21 de março de 2001. Regulamento técnico para rotulagem nutricional obrigatório de alimentos e bebidas embaladas. Diário Oficial da União, Brasília, DF, 23 de mar. Seção 1 , n.40, p.1.

DOMENE, M.A. O papel do ferro sobre a nutrição e a saúde. Disponível em:

<http://www.sic.org.br/nutricao.asp.html>. Acesso em: 15 jul. 2006.

DORNELLES, A.M.G.; MOREIRA, J.R. Qualidade da carne na cadeia produtiva da capivara. In: CONGRESSO NACIONAL DE ZOOTECNIA, 16. 2004, Brasília, Anais... Brasília: Zootec, 2004.

GARCIA, C.A. Avaliação do resíduo de panificação "biscoito" na alimentação de ovinos e nas características quantitativas e 
qualitativas da carcaça. Jaboticabal, 1998, $79 \mathrm{f}$. Dissertação (Mestrado em Zootecnia), Faculdade de Ciências Agrárias e Veterinárias, Universidade Estadual Paulista (Unesp).

\section{GASTALDI, K.A. Taxas de lotação} influenciando a produção ovina. 1996. $118 \mathrm{f}$. Trabalho de conclusão de curso (Graduação em Zootecnia) - Faculdade de Ciências Agrárias e Veterinárias, Universidade Estadual Paulista, Jaboticabal, 1996.

MADRUGA, M.S.; NARAIN, N.; ARRUDA, S.G.B. et al. Influência da idade de abate e da castração nas qualidades físico-químicas, sensoriais e aromáticas da carne caprina. Revista Brasileira de Zootecnia, v.31, n.3, p.1562-1570, 2002.

MADRUGA, M.S.; ARAUJO, W.O.; SOUSA, W.H. et al. Efeito do genótipo e do sexo sobre a composição química e o perfil de ácidos graxos da carne de cordeiros. Revista Brasileira de Zootecnia, v. 35, n.4, p.1838-1844, 2006.

MARCANTONIO, G. A carne do futuro: búfalo. Guaíba: Agropecuária, 1998, 108p.

SAS INSTITUTE. User's Guide to Statistics. Version 6.12. Cary, USA: North Caroline State University, 1996.
PINHEIRO, R.S.B.; SILVA SOBRINHO, A.G.; SOUZA, H.B.A. et al. Composição mineral da carcaça e dos cortes da carcaça de ovinos jovens e adultos. In: CONGRESSO

INTERNACIONAL DE ZOOTECNIA, 4., 2007, Londrina, Anais... Londrina: Zootec, 2007a. CDROM.

PINHEIRO, R.S.B.; SILVA SOBRINHO, A.G.; SOUZA, H.B.A. et al. Informações nutricionais de carnes ovinas em rótulos comerciais, comparativamente às obtidas em análises laboratoriais. Revista Ciência e Tecnologia de Alimentos, v.27, n.2, p.376-381, 2007b.

SILVA, D.J.; QUEIROZ, A.C. Análise de Alimentos: métodos químicos e biológicos. 5.ed. Viçosa: Imprensa Universitária, 2002. $235 p$.

VALLE, E.R. Carne bovina: Alimento nobre indispensável, 2000. Disponível em: <http://www.CNPGL.embrapa.br/publi/divulg/GC D4. html>. Acesso em: 02 fev. 2005. 